\title{
COVID-19 pandemic and the dental practice
}

SADJ April 2020, Vol. 75 No. 3 p119 - p125

S Koutras ${ }^{1}$, S Govender ${ }^{2}$, NH Wood ${ }^{3}$, PD Motloba ${ }^{4}$

\section{ABSTRACT}

Coronavirus disease 2019 (COVID-19), originating in Wuhan, China in December 2019 has become a pandemic affecting numerous countries worldwide, with over 1353 positive cases and 4 deaths confirmed in South Africa thus far.

Dental practitioners are at the forefront of this outbreak through direct and contact transmission via face-to-face communication and through the generation of significant amounts of droplets and aerosols during routine dental procedures, posing potential risks of infection transmission.

There are no guidelines for South African dental practitioners to follow in the time of the COVID-19 pandemic. This paper provides consolidated evidence and best practice on how to prevent and minimise the spread of infection within the dental setting through the use of a flowchart.

The level of evidence provided is based on global recommendations and experience. We conclude that unless dental professionals stick to stringent infection control practices, they are likely to contribute to the spread of the COVID-19.

Author affiliations:

1. Sandra Koutras: $B D S, M S c(D e n t)(O M P), M D e n t(O M P)$, Department of Periodontology and Oral Medicine, School of Oral Health Sciences, Sefako Makgatho Health Sciences University, Pretoria South Africa.

2. Shogan Govender: $B C h D, P D D, M C h D(O M P)$, Department of Periodontology and Oral Medicine, School of Oral Health Sciences, Sefako Makgatho Health Sciences University, Pretoria, South Africa.

ORCID Number: 0000-0003-4470-1530

3. Neil H Wood: $B C h D(U P)$, DipOdont(MFP), MDent(OMP), Department of Periodontology and Oral Medicine, School of Oral Health Sciences, Sefako Makgatho Health Sciences University, Pretoria, South Africa.

ORCID Number: 0000-0001-8950-7999

4. Pagollang D Motloba: BDS, MPH(Epidemiology), MDent(CommDent), MBL, Chief Specialist, Head of Department Community Dentistry, South Africa.

ORCID Number: 0000-0003-1379-7576

Corresponding author: Pagollang D Motloba

Chief Specialist, Head of Department Community Dentistry, South Africa.

Email: pagollang.motloba@smu.ac.za

Author contributions:

1. Sandra Koutras: First draft, diagram, revision, final write-up and final approval - 25\%

2. Shogan Govender: First draft, diagram, revision, final write-up and final approval - 25\%

3. Neil H Wood: Conceptualization, revision, final write-up and final approval - 25\%

4. Pagollang D Motloba: Conceptualization, first draft, revision, final write-up and final approval - $25 \%$

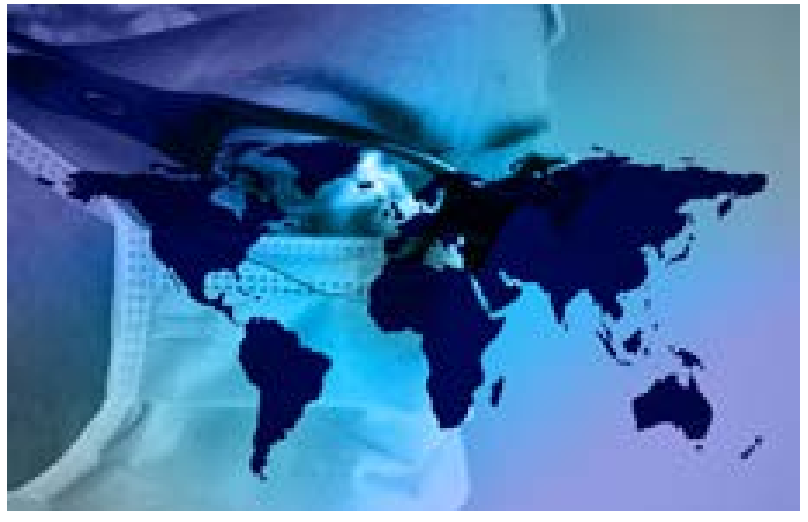

We recommend that during this outbreak, dental professionals consider scaling down on their normal routine, and protect themselves and patients. Focus should be on the management of pain, sepsis and trauma. The epidemic will pass, and dental professionals should outlast the scourge.

\section{Keywords}

Epidemic, pandemic, dentistry, COVID-19, dental professionals, SARS-CoV-2.

\section{INTRODUCTION}

The Coronavirus disease 2019 (COVID-19) pandemic appears to be taking a firmer grip on South Africa with 1353 positive cases and 4 deaths confirmed at the time of writing this article. More oral healthcare practitioners will face the potential transmission of the Severe Acute Respiratory Syndrome Coronavirus 2 (SARS-CoV-2), yet very little information is condensed into appropriate resources and management of this outbreak. In this paper we review the available evidence to deliver the latest information concerning this pandemic facing the oral health professions.

\section{What is an epidemic?}

Our ability to intervene and control the spread of the COVID-19 epidemic is intricately linked with our understanding of the history and course of outbreaks. Epidemics are conditions that prevail extensively among a given population.

These conditions can be contrasted with endemic conditions which are always prevalent among the people in less or subdued rates. Epidemics are characterized by the peaking or fermenting of new or endemic conditions resulting in a significantly greater than normal number of affected individuals in places and periods. 
Several epidemics have plagued humankind since time immemorial, displaying great variations in consequences and malevolence. Yet these conditions display similar and definite features, which explains the anatomy of epidemics and in the case of COVID-19, a pandemic.

1. Epidemics are all fevers, characterized by conditions such as Plague, Yellow Fever, Cholera, Small-Pox, Typhus, Scarlet Fever, Influenza, Ebola and presently COVID-19.

2. Epidemics have a widespread course; prevailing and attacking a large number of people at once or in rapid succession. Hence the tendency to peak exponentially.

3. Epidemics display rapidity in their course, beginning slowly, advancing disjointedly and suddenly striking a major blow, resulting in huge morbidity and or mortality.

4. Epidemics provide a distinct and unmistakable warning; at first these conditions spread violently and suddenly, later resulting in a milder form. This explains the tendency of epidemics to eventually burn out or attenuate in severity.

5. Epidemics result from a transformation of an ordinary disease into a new type of disease. Most recent epidemics can be traced back to changes in diseases occurring in lower animals.

6. Epidemics have a similar manner of migration and course, characterized by periods of quiescence, increase to peak, decrease or decline and disappearance. All epidemics go through these phases repeatedly from one location to the next; from one period to the next.

7. The duration of the epidemic is related to the size of the locality.

8. Epidemics have a short brevity of time from the moment of attack to the recovery or death. Most persons exposed to these conditions will recover in good time... or die therefrom.

9. Epidemics are produced by primary and predisposing causes acting together in unison. The primary cause cannot take effect until the system is weakened or rendered susceptible. The effector agents or predisposing factors (internal or external) contribute to a collapse of the resistance of the body.

The Coronavirus (COVID -19)

- overview of the pandemic

Coronaviruses are a group of viruses known to infect humans and animals; in humans they cause severe respiratory illnesses ranging from common cold-like symptoms to pneumonia.

The most recent coronavirus epidemic, was the Severe Acute Respiratory Syndrome (SARS-CoV) reported in China in 2002. ${ }^{1}$
The present strain of coronavirus, the SARS-CoV-2, recently encountered in humans, originated in Wuhan', and has been named COVID-19. The genetic sequence of COVID-19 shows more than an $80 \%$ identity with SARS-CoV and 50\% with the Middle East respiratory syndrome-related coronavirus (MERS-CoV), ${ }^{3,4}$ both of which originate in bats. ${ }^{5}$ Based on the present epidemiological data, SARS-CoV-2 has higher transmissibility than SARS-CoV and MERS-CoV. ${ }^{6}$

COVID-19 displays all the hallmarks of an epidemic such as fever, a global penetration, rapid and exponential spread; similarity in genetic profile to viruses isolated from lower animals; short latency periods from being asymptomatic, to morbidity, to mortality. Typical of a viral epidemic, the mortality due to COVID- 19 is higher in compromised individuals such as those with underlying co-morbidities such as hypertension, diabetes and cardiovascular disease. ${ }^{7}$ The increase in infection rates is indicative of the initial phase of the epidemic.

It is notable that current available evidence indicates that smoking hastens COVID-19 progression and has a high association with unfavourable outcomes such as admission into ICU, mechanical ventilation and/or death. ${ }^{8}$

The literature is deficient in determining the effect of COVID-19 on vulnerable populations, specifically children. An investigation of 1391 children (aged 16 and younger) for SARS-CoV-2 infections showed that $12.3 \%$ tested positive, with a median age of 6.7 years. Of these, $41.5 \%$ had fever. $^{9}$ Although coughing and pharyngeal erythema were commonly found, $15.8 \%$ of these children had no symptoms or signs of infection. A further 12 showed radiologic signs for pneumonia, but were asymptomatic. In this group, one child (10 months old) passed away.

As things stand, the rising rates of infections are indicative of only the initial phase of the epidemic. The global decrease, decline and disappearance phases of the epidemic may be a long way away.

\section{Management of epidemics}

The management of an epidemic entails all activities to be undertaken, before, during and after the onset of the outbreak. These include the processes which should be involved in order to anticipate or predict the occurrence of an outbreak, enabling preventive measures.

Early detection and surveillance can limit the spread and minimize the impact of the outbreak. Failure to follow these processes often results in dire health, economic and social consequences.

Therefore, coordination among and communication by, all sectors and levels of the State are critical for effective management of an outbreak. Ordinarily, the technical groups, including healthcare professionals, are specifically positioned to detect and manage outbreaks.

These groupings are able to fulfil their responsibilities provided they receive the necessary support and resour- 
ces from the political and public health authorities. Failure in epidemic control is commonly due to failure of authorities and the public to heed the call of the technical experts, more so because their advice tends to infringe on the individual rights and restrict liberties.

\section{Role of the dental profession in the management} of COVID-19

Oral healthcare practitioners carry the greatest risk of COVID-19 acquisition, resulting from face-to-face communication with patients, as well as frequent exposure to body fluids such as saliva and blood together with fomites (such as dental instruments). ${ }^{10}$ Following routine dental procedures, through the use of air- turbine handpieces, low-speed handpieces, ultrasonic scalers, bicarbonate polishers, and polishing cups, as well as, drilling and air sprays inside the oral cavity, a bio-aerosol is created.

Aerosolization occurs when biological particles produced during dental procedures are suspended in gaseous media in the immediate environment, posing a risk in terms of transmission and spread of the virus. Bioaerosols containing infectious microorganisms remain suspended in the air post-treatment in high concentrations, and can spread to inactive dental treatment areas. ${ }^{11,12}$ This in turn increases the risk of exposure to clinicians and patients which can result in the spread of micro-organisms including the SARS-CoV-2. ${ }^{13}$

An in vitro study on the viability of the SARS-CoV-2 virus in aerosol and on different surfaces showed that the virus remains viable for up to 3 hours. ${ }^{12}$ It may be longer as the experiment itself only lasted for 3 hours. When surface viability was assessed, the virus was detected up to 72 hours later. The authors reported that the virus was more stable on plastic and stainless steel surfaces than on copper and cardboard, but present on all nonetheless. This indicates that aerosol and fomite transmission routes are entirely possible. ${ }^{12}$

Therefore, special efforts to protect or reduce transmission should focus on susceptible populations including healthcare providers, and dental professionals in particular. Figure 1 provides clinical guidelines for oral health personnel on measures to prevent the transmission of the virus in their practices. The prevention strategies and precautions are intended to guide clinicians with key clinical activities including the following: patient assessment and treatment procedures, personal hygiene measures, infection control and disinfection, pre-operative rinses, isolation and barrier control techniques, imaging, and waste management. ${ }^{13-17}$

\section{Patient assessment}

It is critical for dentists to establish a pre-treatment assessment point or triage area in their practice. At this designated area, a thorough questioning of the patient should take place (Figure 1). Further investigation, specifically the measurement of temperature should be undertaken. During this assessment, patients and their entourage must be supplied with masks to restrict transmission of secretion.
The number of persons accompanying patients (in the case of minors or the elderly) should be limited to one.18,19 The patient waiting area should be well ventilated, with a one metre separation between patients (social distancing).

Based on the level of risk estimated, the patients should be triaged to relevant service centres including hospitals for further management. ${ }^{20} \mathrm{It}$ is advisable that only "emergencies" should be attended to. This includes the management of pain, sepsis or trauma.

It is important to note that fever can be associated with acute dental infection. The use of aerosol-producing instruments should be avoided. Any elective or nonessential procedures should be postponed to after the outbreak.

For suspected/confirmed cases of COVID-19 who require urgent dental treatment, procedures should be performed within a negative pressure room with a minimum of 12 air changes per hour to facilitate ventilation, as per the World Health Organization's recommendations. ${ }^{20}$ Mechanical ventilation should also be initiated between patients. Personal protective equipment of the highest standard should be utilised at all times.

\section{Personal hygiene measures}

\subsection{Hand hygiene}

The importance of handwashing for twenty seconds is critical in the prevention of infection transmission. The cleansing of hands can be performed with either soap and water or an alcohol-based hand rub. ${ }^{21}$

Hand hygiene should be performed before touching a patient, before any procedure, after exposure to body fluids, after touching a patient, and after touching a patient's surroundings. ${ }^{22}$

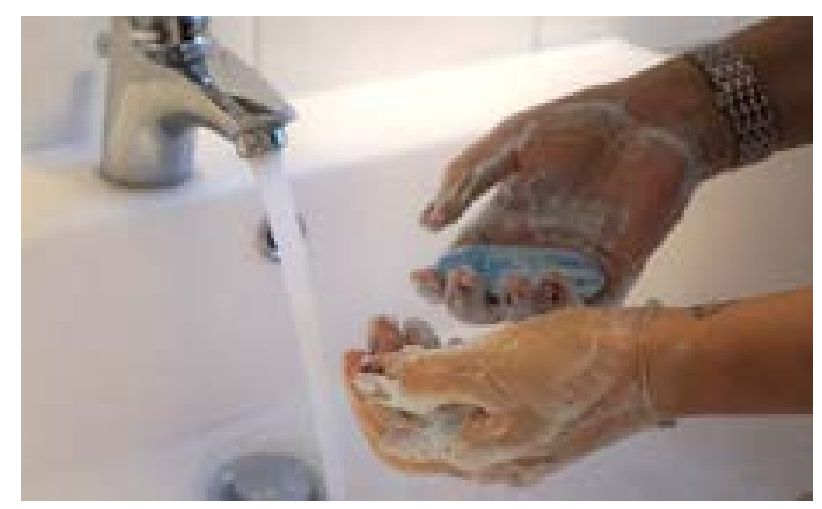

\subsection{Personal protective equipment (PPE)}

Preventing fine and ultrafine particle exposure can only be achieved through the use of high level personal protective equipment. ${ }^{22,23}$

\section{(i). Goggles/face-shields}

The spread of oral microorganisms during oral procedures radiates mostly towards the inner part of the eyes and around the nose. ${ }^{24}$ COVID-19 may also be transmitted through the conjunctiva receiving infectious 
President Cyril Ramaphosa declared a national state of disaster in light of the novel Coronavirus pandemic which has spread to numerous countries with the number of confirmed cases and deaths steadily rising. One thousand three hundred and fifty three cases and four deaths (23 March 2020) are confirmed in South Africa.

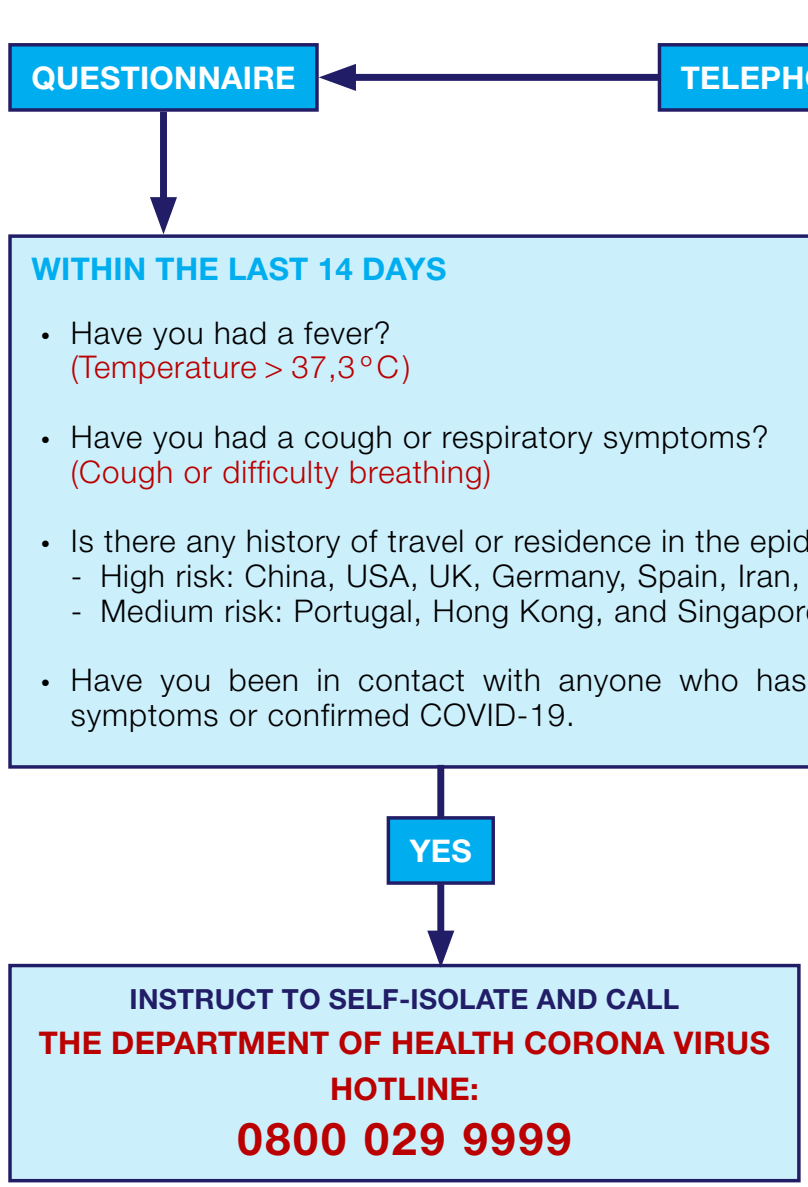

HIGHER RISK INDIVIDUALS:

- Males.

- Individuals $>60$ years old.

- With Comorbidities:

- Diabetes.

- Hypertension.

- Cardio-vascular diseases.

- Immune-compromised individuals.

- Positive response to questionnaire.

- Having travelled from epidemic areas.

PPE (Personal Protective Equipment includes:

- PPE (Personal Protective Equipment) includes:

- Headwear, face shield/goggles, N95 mask, disposable gowns, closed shoes. Hand hygiene is imperative at all times.
DENTAL TRIAGE

\section{ORAL / DENTAL EMERGENCIES*}

- Pain, Trauma, Sepsis/Infection, or

- Cases where non-treatment would inhibit normal oral function to the extent where this will negatively impact a patient's health in the next three to six months. Dentists will use their professional judgment to treat patients in this category.

\section{ORAL / DENTAL EMERGENCIES*}

- Important to ensure:

- Rubber dam use

- High volume suction use

- Extra-oral imaging (preferable)

- The use of aerosol producing instruments/ equipment to be avoided as far as possible

- Well-ventilated surgery

- 4 - handed dentistry

- Disinfect all equipment and surfaces with alcohol [>70\%]

- Chlorine containing disinfectants on floors and walls

- Discard PPE after each patient

- Educate patient regarding COVID-19 and transmission

- Patients to be unaccompanied unless elderly or minor

- Schedule longer appointments to facilitate optimal infection control procedures

Figure 1. Triage schematic for Dental professionals 
Adequate prevention can be achieved through the implementation of stringent control measures to curb the spread of the virus as the risk of cross infection is high. The following flowchart provides some guidance to the practitioner on how to manage patients, staff, and the workplace during this SARS-CoV-2 outbreak. Also consult the NCID website: www.ncid.ac.za.

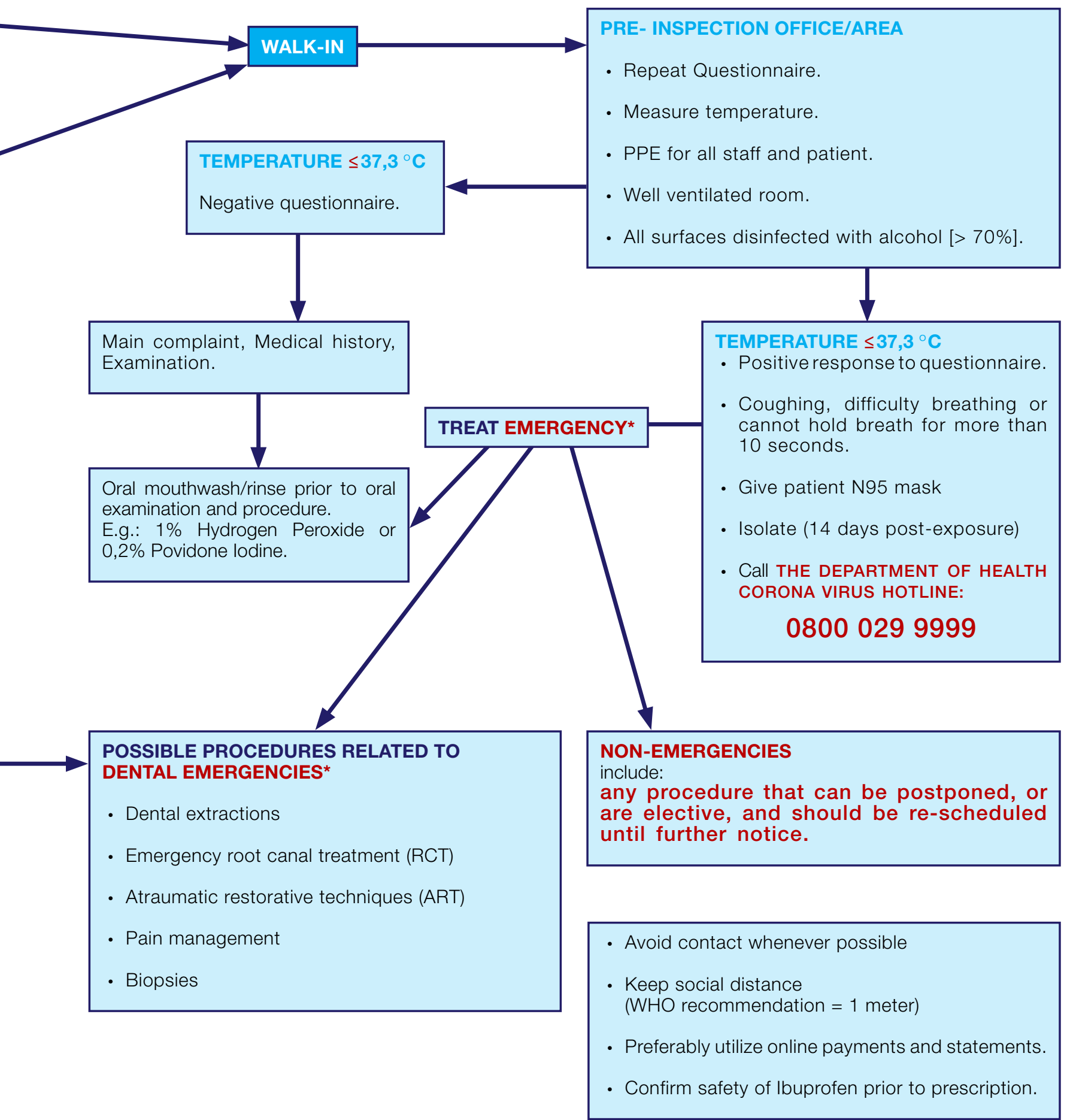


droplets. ${ }^{25}$ It is for this reason that protective eyewear or face-shields should be worn and should be disinfected between procedures.

\section{(ii). Face masks}

A National Institute for Occupational Safety and Health (NIOSH)-certified N95, European Standard Filtering Face Piece 2 (EU FFP2), or equivalent mask should be used.

N95 respirator masks have been shown to filter at least 95\% of airborne particles with an aerodynamic diameter of 0.3 um or above, but are not resistant to oil particles.

It should be noted that there is no standard test for nanoparticle penetration on respirators. However, the improper use of the mask and the possibility of leakage around the mask seal could negate the intended effect of the mask.

It is also important to note the variability of these masks in relation to the manufacturer as different N95 models may differ in shape, and whether they have an exhalation valve or not. ${ }^{26}$

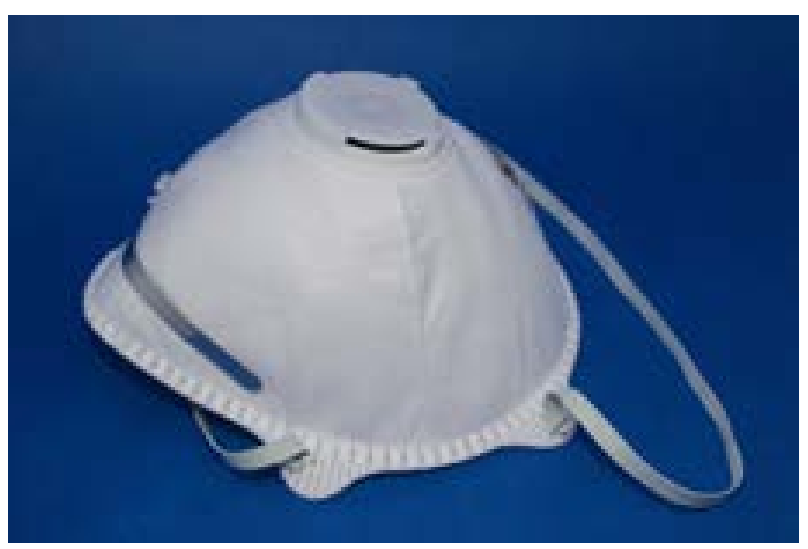

\section{Infection control and disinfection}

Droplets containing infective agents produced during aerosol generating procedures deposit on the surrounding surfaces and can persist for days. Biocidal surface disinfectants containing $62 \%-71 \%$ ethanol, $0.5 \%$ hydrogen peroxide, and $0.1 \%$ ( $1 \mathrm{~g} / \mathrm{L})$ sodium hypochlorite should be used for a period of one minute to disinfect the dental surgery between patients.

27 Items which should be disinfected include and are not limited to the dental chair, cabinet tops, taps, door handles, blood pressure cuffs as well as computer keyboards/mouse, pens and cell phones.

Other steps taken to reduce aerosol contamination include: ${ }^{24}$

- Disinfection of the water line to the dental chair equipment.

- Sterilization of all dental treatment machines and instruments.

- Installation of a valve and strainer in the dental chair to prevent sucking reintegration infected liquid, aerosols and particulate materials.

\section{Additional treatment regimen}

The universal use of pre-procedural rinses and highvolume evacuations is recommended in addition to standard infection control barriers such as PPE, as a means of reducing infection risk. Pre-operative mouth rinsing, usually through the use of Chlorhexidine $0.12 \%$, has been shown to reduce the microbial count. ${ }^{28}$

Unfortunately, this antiseptic mouthwash may not be effective in killing SARS-CoV-2. ${ }^{6}$ Due to the vulnerability of the virus to oxidation, the use of $1 \%$ hydrogen peroxide or $0.2 \%$ povidone have been recommended as alternatives prior to any dental procedure.6,29 Rubber dam isolation eliminates up to $98.5 \%$ of the microbial content within aerosols, ${ }^{30,31}$ and for this reason should be used during every procedure. The use of a high-volume evacuator further diminishes the aerosol produced. ${ }^{28}$

\section{Imaging and radiography}

Dental imaging, which is generally used as the main diagnostic aid by dental professionals should be limited to extra-oral imaging where possible. This diminishes pooling of saliva and gagging reflex. ${ }^{6}$

\section{Medical waste management}

All disposable personal protective equipment should be discarded into the infectious waste bin which should be collected and discarded according to established waste management protocols. Reusable items and instruments should be sterilized as per the Asia Specific Society for Infection Control (APSIC) guidelines for disinfection and sterilization of instruments in health care facilities. ${ }^{6}$

\section{CONCLUSION}

It is prudent for dentists to keep abreast with the developments around the COVID-19, in order that they may institute appropriate clinical practice which will ensure maximum protection for themselves, staff and patients.

The decision about the nature and level of service to be provided remains the prerogative of each practitioner depending on the level of risk assessment and the readiness of the practice.

Figures are correct as reported on day of sending to print.

\section{References}

1. Yin $Y$, Wunderink RG. MERS, SARS and other coronaviruses as causes of pneumonia. Respirology. 2018; 23: 130-7.

2. Hui DS, Madani TA, Ntoumi F, et al. The continuing 2019-nCoV epidemic threat of novel coronaviruses to global health - the latest 2019 novel coronavirus outbreak in Wuhan, China. Int J Infect Dis. 2020: 91: 264-6.

3. Hussin AR, Siddappa NB. The epidemiology and pathogenesis of coronavirus disease (COVID-19) outbreak. Journal of Autoimmunity. 2020. https://doi.org/10.1016/j.jaut.2020. 102433.

4. Lu R, Zhao X, Li J, et al. Genomic characterization and epidemiology of 2019 novel coronavirus: implications for virus origins and receptor binding. Lancet. 2020; 395 (10224): 565-74. 
5. Cui J, Li F, Shi LZ. Origin and evolution of pathogenic coronaviruses. Nat Rev Microbiol. 2019; 17: 181-92.

6. Peng X, Xu X, Li Y, et al. Transmission routes of 2019-nCoV and controls in dental practice. International Journal of Oral Science. 2020; 12(1): 1-6.

7. Wang D, Hu B, Hu C, et al. Clinical characteristics of 138 hospitalized patients with 2019 novel coronavirusinfected pneumonia in Wuhan, China. JAMA 2020 doi: 10.1001/ jama.2020.1585. [epub ahead of print 7 Feb 2020] in press.

8. Vardavas Cl, Nikitara K. COVID-2019 and smoking: A systematic review of the evidence. Tob Induc Dis. 2020; 18 (March) 2020.

9. Lu $X$, Zhang $L, D u H$, et al. SARS-CoV-2 infection in children. N Engl J Med. 2020; DOI:10.1056/NEJMc2005073.

10. Chan JF, Yuan S, Kok KH, et al. 2020. A familial cluster of pneumonia associated with the 2019 novel coronavirus indicating person-to-person transmission: a study of a family cluster. Lancet. 202: 0395(10223): 514-23.

11. Ahmed MS, Girish DB, Devi RE, et al. (2020). Dental considerations in Corona Virus Infections: First review in literature. Journal of Advanced Medical and Dental Sciences Research. 2020 http://doi.org/10.1371/journal.pone. 0225644.21276/jamdsr.

12. Van Doremalen N, Bushmaker T, Morris DH, et al. Aerosol and surface stability of SARS-CoV-2 as compared with SARS-CoV-1. NEJM 2020; http://doi.org/10.1371/journal. pone.0225644.1056/NEJMc2004973.

13. Ling ML, Ching P, Widitaputra A, et al. APSIC guidelines for disinfection and sterilization of instruments in health care facilities. Antimicrobial Resistance \& Infection Control. 2018; 7(1): 25.

14. Harrel SK, Molinari J. Aerosols and splatter in dentistry: a brief review of the literature and infection control implications. JADA. 2004; 135: 429-37.

15. Cleveland JL. et al. Transmission of blood-borne pathogens in US dental health care settings: 2016 update. JADA. 2016; 147: 729-38.

16. Rajput R, Chouhan Z, Suthar P, et al. MERS-CoV (middle east respiratory syndrome corona virus): a dental surgeon perspective. International Journal of Contemporary Medical Research. 2015; 2(5): 1228 - 30.

17. Meng L, Hua F, Bian Z. Coronavirus Disease 2019 (COVID -19): Emerging and future challenges for dental and oral medicine. J Dent Res. 2020. doi:10.1177/00220345209142 46.

18. Liu MH, Chen CT, Chuang L, et al. Removal efficiency of central vacuum system and protective masks to suspended particles from dental treatment. PLoS ONE. 2019; 14(11): e0225644. http://doi.org/10.1371/journal.pone.0225644

19. Kohn WG, Collins AS, Cleveland JL et al. Centers for Disease Control and Prevention. 2003. Guidelines for infection control in dental health-care settings. 2003. https://www. cdc.gov/mmwr/preview/mmwrhtml/rr5217a1.htm

20. World Health Organization. Clinical management of severe acute respiratory infection when novel coronavirus (2019$\mathrm{nCoV}$ ) infection is suspected: interim guidance [accessed 2020 Feb 17]. https://www.who.int/publications-detail/clinical-management-of-severe-acute-respiratory-infection-when -novel-coronavirus-(ncov)-infection-is-suspected.

21. Ge ZY, Yang LM, Xia JJ, et al. Possible aerosol transmission of COVID-19 and special precautions in dentistry. Journal of Zhejiang University-SCIENCE B. 2020; 1-8.

22. WHO, 2009. WHO Guidelines on Hand Hygiene in Health Care: First Global Patient Safety Challenge - Clean Care is Safer Care. World Health Organization, Geneva, Switzerland.

23. Larson EL, Early E, Cloonan P, et al. An organizational climate intervention associated with increased handwashing and decreased nosocomial infections. Behav Med. 2000; 26(1): 14-22.

24. Nejatidanesh F, Khosravi Z, Goroohi H, et al. Risk of contamination of different areas of dentist's face during dental practices. Int J Prev Med. 2013; 4(5): 611-5.
25. Lu CW, Liu XF, Jia ZF. 2019-nCoV transmission through the ocular surface must not be ignored. Lancet 2020; 395(10224): 39. https://doiorg/10.1016 S0140-6736(20)30 313-5.

26. Ntlailane MGL, Wichmann J. Effectiveness of N95 respirators for nanoparticle exposure control (2000-2016): A systematic review and meta-analysis. J Nanopart Res. 2019; 21: 170. http://doi.org/10.1007/s11051-019-4596-0.

27. Kampf G, Todt D, Pfaender S, et al. 2020. Persistence of coronaviruses on inanimate surfaces and their inactivation with biocidal agents. J Hosp Infect. 2020; https://doi.org/ 10.1016/j.jhin.2020.01.022.

28. Narayana TV, Mohanty L, Sreenath G, et al. Role of pre-procedural rinse and high volume evacuator in reducing bacterial contamination in bioaerosols. JOMFP. 2016; 20(1): 59.

29. Maki DG, Hassemer CA. Flash sterilization: carefully measured haste. Infect Control. 1987; 8: 307-10.

30. Cochran MA, Miller $\mathrm{CH}$, Sheldrake MA. The efficacy of the rubber dam as a barrier to the spread of micro-organisms during dental treatment. JADA. 1989; 199: 141-4.

31. Evans D, Samaranayake LP, Reid J. The use of rubber dam in reducing atmospheric contamination. J Dent Child. 1989; 56: $442-4$ 